\title{
APPLICATION OF FUZZY LOGIC FOR CONTROLLING MECHANISM OF RELATIVE MANIPULATION ROBOT (MRM ROBOT)
}

\author{
Phan Bui Khoi ${ }^{1}$, Nguyen Van Toan ${ }^{2}$ \\ ${ }^{1}$ Hanoi University of Science and Technology, No.1 DaiCoViet Street, Hai Ba Trung, Hanoi \\ ${ }^{2}$ Korea Institute of Science and Technology, 5 Hwarang-ro 14-gil, Seongbuk-gu, \\ Seoul, Republic of Korea ${ }^{2}$
}

Email: khoi.phanbui@hust.edu.vn; toan70411hd91@gmail.com

Recieved: 26 October 2015; Accepted for publication: 20 February 2016

\begin{abstract}
In robot control, mathematical equations describing dynamic behaviors of robots are usually complicated. Additionally, the components such as inertial and friction parameters appearing in these equations are very difficult to determine exactly. With robots having complex structure such as parallel robots, MRM robots etc., the derivation of dynamic equations becomes more difficult and sometimes cannot obtain analytically. In those cases, controlling robot based on its equations of motion is quite hard. Applying fuzzy logic for robot control can overcome the mentioned drawbacks. This is because fuzzy control algorithm gives favorable condition to deal with the lack of adequation as well as inaccuracy of components in robot's dynamic equations. Furthermore, the fuzzy rules are created by clauses which based on human logic, so it is easily to understand and implement. This paper discusses the application of fuzzy logic for controlling MRM robots. To compare the results obtained from fuzzy control, this paper are also adressed the use of the computed torque algorithm to control MRM robots.
\end{abstract}

Keywords: mechanism of relative manipulation robot (MRM robot), fuzzy logic, fuzzy control.

\section{INTRODUCTION}

In $[1, \ldots, 5]$, the model of MRM robot was introduced. Basically, the proposed MRM robot include two serial/parallel robots to cooperate of each other for serving a desired purpose: a master robot (we call first robot or tool-robot) brings the tool (example as drilling machine) and a slave robot (we call second robot or jig-robot) brings a jig used to hold manipulated object. MRM robot performs manipulations to the object when both two robot mechanisms work together and tool-robot manipulates to object which follow relative movements between two mechanisms.

Controlling manipulations of MRM robots can be realized by classic method. First of all, inverse kinematics of the MRM robot must be solved numerically/anatically. In the next step, 
MRM robot's dynamic equations are established based on multibody dynamics theory using the Lagrangian method or Newton-Euler method or principle of compatibility etc. Thanks to kinematical results and dynamical equations of robot, the well known control algorithms such as computed torque or feedward+PD/PID are applied to control robot. It can be pointed out that these methods have disadvantages in constructing control module because dynamic equations of MRM robots are too complicated. In addition, inertial parameters as well as friction parameters in dynamical equations are not able to determine exactly.

Based on the way of human thinking and processing information [6], fuzzy logic brings several benefits in controlling engineering systems. To design fuzzy control module, the first step is determining input and output of control module, fuzzificating input and output. Then control law and composite law are established and the last step is defuzification. All those steps are independent with dynamical equations of control object. Several authors applied fuzzy logic to control field and achieved positive results, for example [7-11]. To the best of our knowledge, however, applying fuzzy logic for controlling MRM robots is not considered in literature. This paper will discuss the use of the fuzzy method to control MRM robot. The results obtained from fuzzy method is compared to the results obtained based on the computed torque control method. All of control modules are designed in MATLAB/SIMULINK environment for real-time simulation and control purposes.

\section{MRM ROBOT'S MANIPULATION MOTION}

The Figure 1 presents 5-DOF MRM robot model which is used for welding (or lazer machining) purpose, including 3-DOF tool-robot and 2-DOF jig-robot. Tool-robot consists of the base platform, denoted by the number $\mathrm{L}_{10}$ and movable links, denoted by numbers $\mathrm{L}_{11}, \mathrm{~L}_{12}$ and $\mathrm{L}_{13}$, respectively. Jig-robot consists of another base platform, denoted by number $\mathrm{L}_{20}$ and two movable links $\mathrm{L}_{21}$ and $\mathrm{L}_{22}$.

The motion of links: $\mathrm{L}_{11}$ rotates around $\mathrm{z}_{10}, \mathrm{~L}_{12}$ rotates around $\mathrm{z}_{11}, \mathrm{~L}_{13}$ translates along $\mathrm{z}_{12}$, $\mathrm{L}_{21}$ rotates around $\mathrm{z}_{20}$ and $\mathrm{L}_{22}$ rotates around $\mathrm{z}_{21}$. The first three DOFs of the tool-robot allow it to bring welding tool to any position in its workspace while orientation of welding tool axis is always parallel to $\mathrm{z}_{10}$. Besides, 2-DOF jig-robot allows the rotation around two perpendicular axes, gives ability to control manipulation orientation vertically to tool-robot realize manipulations. The collaboration between two mechanisms brings the flexibility for controlling manipulation's position and orientation.

The inertial frame $\mathrm{x}_{10} \mathrm{y}_{10} \mathrm{z}_{10}$ is used to as the fixed Catersian coordinate system. To describe position and orientation of any link of the robot, the standard Denavit-Hartenberg method is applied. The coordinate systems are showed on Figure 1, the kinematic parameters of the toolrobot and the jig-robot are presented in Table 1 and 2, respectively. Considering tool-robot, the following transformation is used: $x_{10} y_{10} z_{10} \rightarrow x_{11} y_{11} z_{11} \rightarrow x_{12} y_{12} z_{12} \rightarrow x_{13} y_{13} z_{13}$ in which transformation matrices are defined as: ${ }^{0} \mathrm{~A}_{11}\left(\theta_{11}\right),{ }^{1} \mathrm{~A}_{12}\left(\theta_{12}\right)$, and ${ }^{2} \mathrm{~A}_{13}\left(\theta_{13}\right)$. As a result, position and orientation of the end-effector in the fixed frame are determined by the following matrix:

$$
{ }^{0} A_{13}={ }^{0} A_{11}\left(\theta_{11}\right){ }^{1} A_{12}\left(\theta_{12}\right){ }^{2} A_{13}\left(\theta_{13}\right)
$$

Similarly, for the case of Jig-robot we have following transformation chain: $x_{10} y_{10} z_{10} \rightarrow x_{21} y_{21} z_{21} \rightarrow x_{22} y_{22} z_{22}$ with transformation matrices respectively ${ }^{10} \mathrm{~A}_{20},{ }^{0} \mathrm{~A}_{21}\left(\theta_{21}\right)$, ${ }^{1} \mathrm{~A}_{22}\left(\theta_{22}\right)$. One leads to: 


$$
{ }^{0} \mathrm{~A}_{22}={ }^{10} \mathrm{~A}_{20}{ }^{0} \mathrm{~A}_{21}\left(\theta_{21}\right){ }^{1} \mathrm{~A}_{22}\left(\theta_{22}\right)
$$

the workpiece is clamped on the table $\mathrm{L}_{22}$ with the configuration of the machining object identified in the frame $\mathrm{x}_{22} \mathrm{y}_{22} \mathrm{Z}_{22}$. Using the kinematic parameters to describe the position and orientation of the end-effector in the $\mathrm{x}_{22} \mathrm{y}_{22} \mathrm{Z}_{22}$ frame:

$$
\mathrm{p}=\left[\mathrm{p}_{1}, \mathrm{p}_{2}, \ldots, \mathrm{p}_{6}\right]^{\mathrm{T}}=\left[{ }^{22} \mathrm{x}_{\mathrm{p} 13},{ }^{22} \mathrm{y}_{\mathrm{p} 13},{ }^{22} \mathrm{z}_{\mathrm{p} 13},{ }^{22} \alpha_{\mathrm{p} 13},{ }^{22} \beta_{\mathrm{p} 13},{ }^{22} \eta_{\mathrm{p} 13}\right]^{\mathrm{T}}
$$

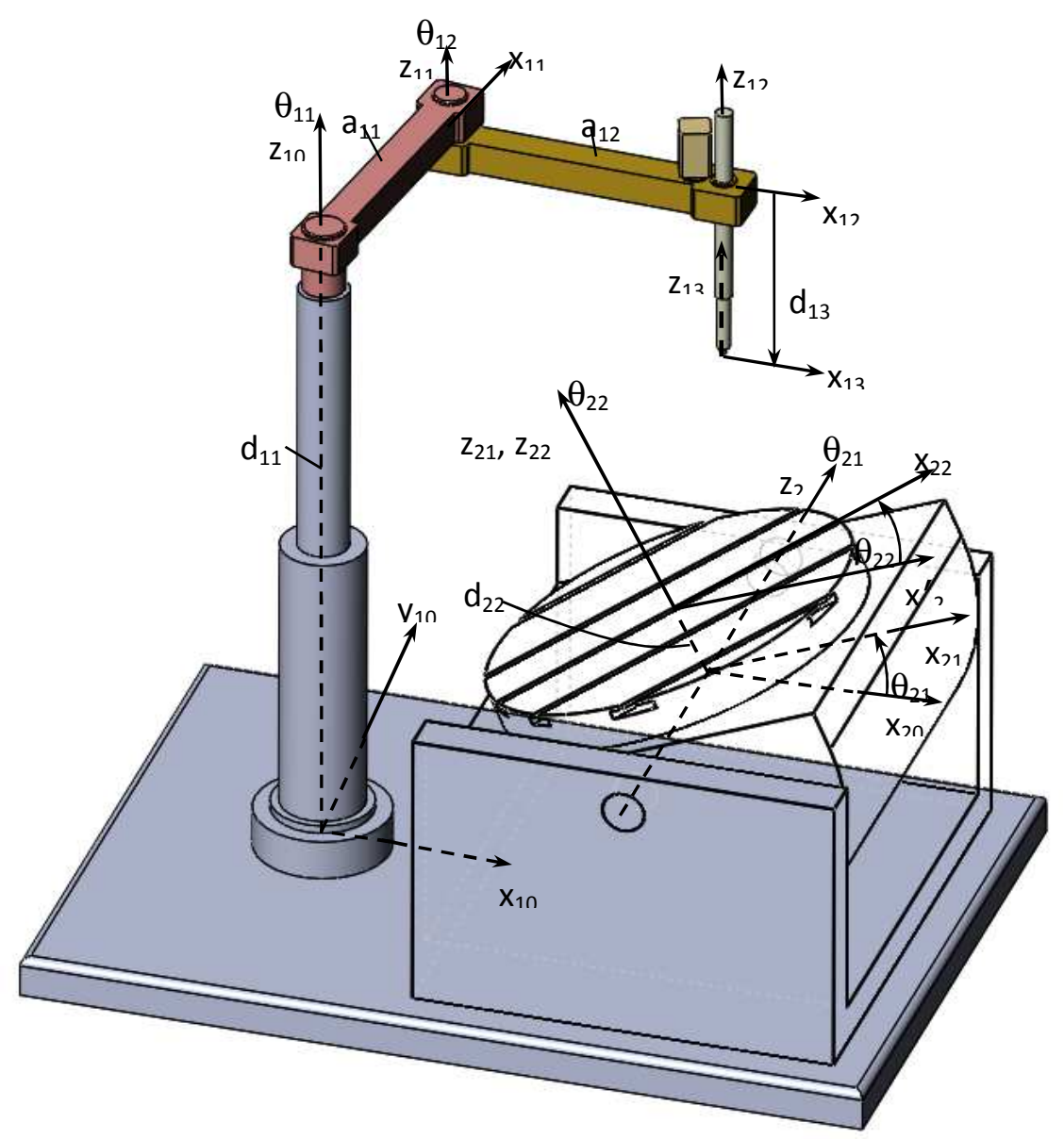

Figure 1. MRM Robot model and coordinate systems.

MRM robot's DH parameters are presented in Table 1 and Table 2, with Table 1 presents DH parameters of tool-robot and Table 2 presents DH parameters of jig-robot.

Table 1. Table of tool-robot's DH parameters.

\begin{tabular}{|c|c|c|c|c|}
\hline Link Parameter & $\theta_{\mathrm{i}}$ & $\mathrm{d}_{\mathrm{i}}$ & $\mathrm{a}_{\mathrm{i}}$ & $\alpha_{\mathrm{i}}$ \\
\hline 11 & $\theta_{11}$ & $\mathrm{~d}_{11}$ & $\mathrm{a}_{11}$ & 0 \\
\hline 12 & $\theta_{12}$ & 0 & $\mathrm{a}_{12}$ & 0 \\
\hline 13 & 0 & $\mathrm{~d}_{13}$ & 0 & 0 \\
\hline
\end{tabular}


Table 2. Table of jig-robot's DH parameters.

\begin{tabular}{|c|c|c|c|c|}
\hline Link & $\theta_{\mathrm{i}}$ & $\mathrm{d}_{\mathrm{i}}$ & $\mathrm{a}_{\mathrm{i}}$ & $\alpha_{\mathrm{i}}$ \\
\hline 20 & 0 & $\mathrm{~d}_{20}$ & $\mathrm{a}_{20}$ & $-90^{0}$ \\
\hline 21 & $\theta_{21}$ & 0 & 0 & $90^{0}$ \\
\hline 22 & $\theta_{22}$ & $\mathrm{~d}_{22}$ & 0 & 0 \\
\hline
\end{tabular}

It can also be shown the position and orientation of the frame $x_{13} y_{13} z_{13}$ with respect to frame $\mathrm{x}_{22} \mathrm{y}_{22} \mathrm{Z}_{22}$ as follows:

$$
{ }^{22} \mathrm{~A}_{13}(\mathrm{p})=\left[\begin{array}{cccc}
\mathrm{c}_{\mathrm{p} 11}(\mathrm{p}) & \mathrm{c}_{\mathrm{p} 12}(\mathrm{p}) & \mathrm{c}_{\mathrm{p} 13}(\mathrm{p}) & { }^{22} \mathrm{x}_{\mathrm{p} 13} \\
\mathrm{c}_{\mathrm{p} 21}(\mathrm{p}) & \mathrm{c}_{\mathrm{p} 22}(\mathrm{p}) & \mathrm{c}_{\mathrm{p} 23}(\mathrm{p}) & { }^{22} \mathrm{y}_{\mathrm{p} 13} \\
\mathrm{c}_{\mathrm{p} 31}(\mathrm{p}) & \mathrm{c}_{\mathrm{p} 32}(\mathrm{p}) & \mathrm{c}_{\mathrm{p} 33}(\mathrm{p}) & { }^{22} \mathrm{z}_{\mathrm{p} 13} \\
0 & 0 & 0 & 1
\end{array}\right]=\left[\begin{array}{cc}
\mathrm{C}_{\mathrm{p}}(\mathrm{p}) & \mathrm{r}_{\mathrm{p}} \\
0^{\mathrm{T}} & 1
\end{array}\right]
$$

The other way to describe the position and orientation of the end-effector, frame $\mathrm{x}_{13} \mathrm{y}_{13} \mathrm{z}_{13}$, with respect to fixed frame $\mathrm{x}_{10} \mathrm{y}_{10} \mathrm{Z}_{10}$ as follows:

$$
{ }^{0} \mathrm{~A}_{23}={ }^{10} \mathrm{~A}_{20}{ }^{0} \mathrm{~A}_{21}\left(\theta_{21}\right){ }^{1} \mathrm{~A}_{22}\left(\theta_{22}\right){ }^{22} \mathrm{~A}_{13}(\mathrm{p})
$$

From the equations (1), (5) we see that both two matrices ${ }^{0} \mathrm{~A}_{13},{ }^{0} \mathrm{~A}_{23}$ describe the position and orientation of the frame $\mathrm{x}_{13} \mathrm{y}_{13} \mathrm{z}_{13}$ with respect to fixed frame $\mathrm{x}_{10} \mathrm{y}_{10} \mathrm{z}_{10}$, we obtain:

$$
{ }^{22} \mathrm{~A}_{13}(\mathrm{p})={ }^{10} \mathrm{~A}_{20}^{-10} \mathrm{~A}_{21}^{-11} \mathrm{~A}_{21}^{-10} \mathrm{~A}_{11} \cdots{ }^{2} \mathrm{~A}_{13}=\left[\begin{array}{cccc}
\mathrm{c}_{\mathrm{q} 11}(\mathrm{q}) & \mathrm{c}_{\mathrm{q} 12}(\mathrm{q}) & \mathrm{c}_{\mathrm{q} 13}(\mathrm{q}) & { }^{22} \mathrm{x}_{\mathrm{q} 13}(\mathrm{q}) \\
\mathrm{c}_{\mathrm{q} 21}(\mathrm{q}) & \mathrm{c}_{\mathrm{q} 22}(\mathrm{q}) & \mathrm{c}_{\mathrm{q} 23}(\mathrm{q}) & { }^{22} \mathrm{y}_{\mathrm{q} 13}(\mathrm{q}) \\
\mathrm{c}_{\mathrm{q} 31}(\mathrm{q}) & \mathrm{c}_{\mathrm{q} 32}(\mathrm{q}) & \mathrm{c}_{\mathrm{q} 33}(\mathrm{q}) & { }^{22} \mathrm{z}_{\mathrm{q} 13}(\mathrm{q}) \\
0 & 0 & 0 & 1
\end{array}\right]
$$

Equation (6) is known as the kinematic equation of robot in matrix form. This representation shows the relationship between the MRM robot's relative manipulation motion, which is described by six relative operational coordinates between frames $x_{22} y_{22} z_{22}$ and frame $x_{13} y_{13} z_{13}$ (3), and the motion of the robot links, which is described by five joint coordinates as follows:

$$
\mathrm{q}=\left[\mathrm{q}_{1}, . ., \mathrm{q}_{5}\right]^{\mathrm{T}}=\left[\theta_{11}, \theta_{12}, \theta_{13}, \theta_{21}, \theta_{22}\right]^{\mathrm{T}}
$$

Given the joint coordinates, we can compute the relative operational coordinates of the matrix ${ }^{22} \mathrm{~A}_{13}$. On the other hand, given the relative operational coordinates of frame $\mathrm{x}_{13} \mathrm{y}_{13} \mathrm{z}_{13}$ with respect to frame $\mathrm{x}_{22} \mathrm{y}_{22} \mathrm{Z}_{22}$ (3), we can solve inversely kinematic problem to compute the joint coordinates (7) [2].

Applying the same method of kinematic investigation in paper [2] when using MRM robot for welding process is showed on Figure 2. Machine part 2 is on jig-robot's table 1 what is welded with tube 3 follow butt weld 4, with parameters:

- The path of the butt weld 4 is intersection of tube surface with machine part's surface 5, is a parallel plane with $\mathrm{y}_{22}$ axis and slope an angle $\gamma$ to the horizontal plane.

- The tube axis $\mathrm{z}$ is perpendicular to the surface 5 . 
- Center $\mathrm{O}$ of welding path's circle have coordinates $\left(\mathrm{x}_{0}, \mathrm{y}_{\mathrm{o}}, \mathrm{z}_{\mathrm{o}}\right)$ in the frame $\mathrm{x}_{22} \mathrm{y}_{22} \mathrm{z}_{22}$, radius of the tube is $r$.

- The axis of welding tool (welding gun) $\mathrm{z}_{13}$ is coplanar and sloping an angle $\lambda$ with tube axis.

- The velocity of welding tool's head along welding path is $\mathrm{v}_{\mathrm{h}}$ which is given base on welding engineering requirement.

1. jig-robot's table

2. machine part

3. tube

4. welding path

5. machine part's surface

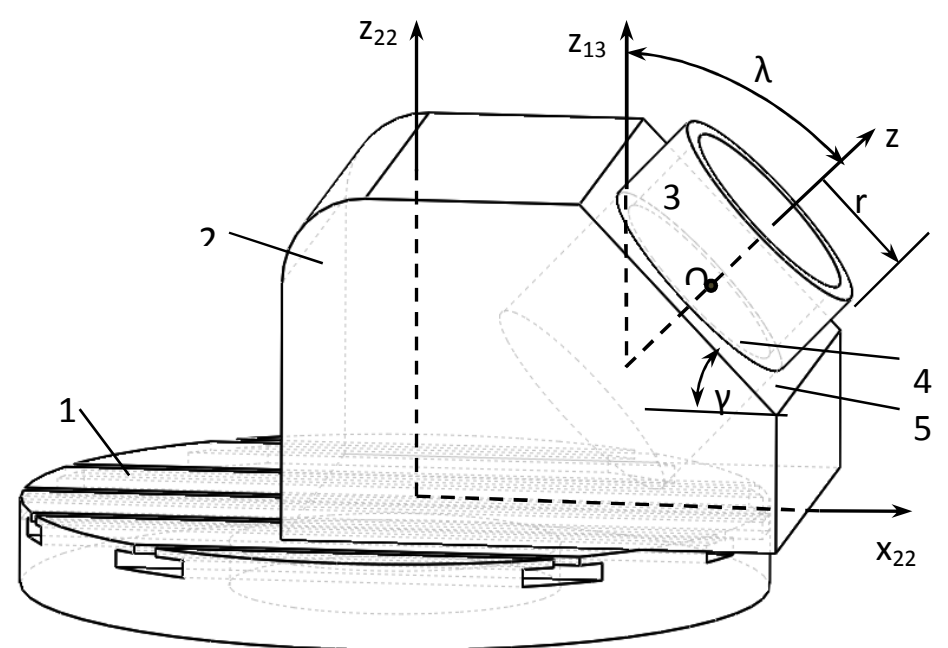

Figure 2. Welding path is realized by MRM robot.

Table 3 shows the parameters appearing in this application.

Table 3. Parameters describe the machining object.

\begin{tabular}{|c|c|c|c|c|c|c|}
\hline$\gamma$ & $\mathrm{x}_{\mathrm{o}}$ & $\mathrm{y}_{\mathrm{o}}$ & $\mathrm{z}_{\mathrm{o}}$ & $\mathrm{r}$ & $\lambda$ & $\mathrm{v}_{\mathrm{h}}$ \\
\hline $30^{0}$ & $0.1(\mathrm{~m})$ & $0.1(\mathrm{~m})$ & $0.1(\mathrm{~m})$ & $0.07(\mathrm{~m})$ & $45^{0}$ & $0.02(\mathrm{~m} / \mathrm{s})$ \\
\hline
\end{tabular}

By virtue of above requirements, the relative manipulation motion of the end-effector (the welding gun) can be obtained and described by coordinates (3) and their derivatives. Based on these results and kinematic equation (6), the well known algorithms such as Newton-Raphson is applied to solve inverse kinematics and obtain trajectory and velocity of MRM robot's links. Files Position.txt, Velocity.txt, Acceleration.txt are exported with purpose as input data for control.

\section{MRM ROBOT'S DYNAMICAL EQUATIONS}

While the robot performs the operation, the kinematical constraint, which is imposed by relative manipulation motion, will form the kinematical close-loop chain.The Figure 3 presents the closed-loop MRM robot's structure.

Although kinematic structure is closed-loop, we observe that the dynamic equations of motion can be formulated in terms of independent generalized coordinates (7). Utilizing the 
principle of compatibility as shown in $[3,4,5,12,13]$ the robot dynamic equations of motion are written as follows:

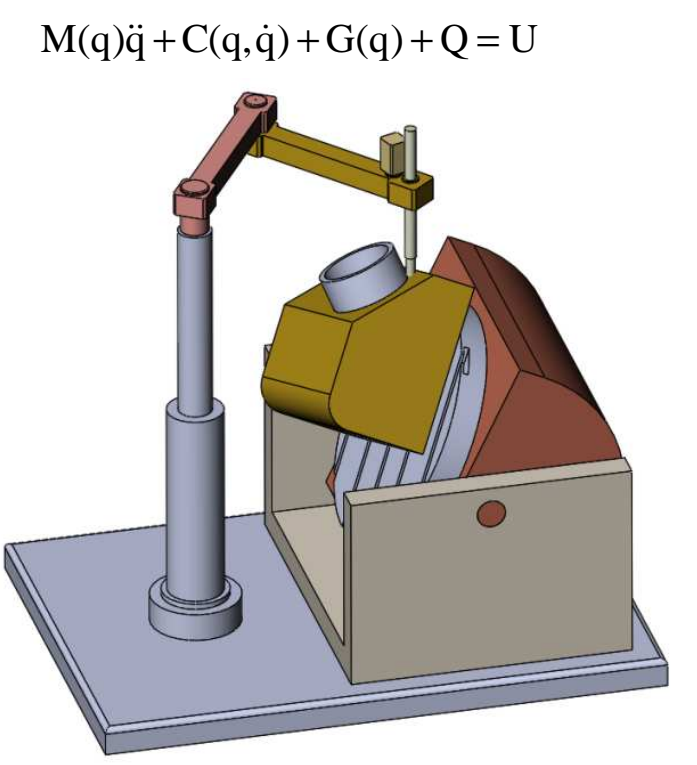

Figure 3. closed-loop kinematic chain of MRM robot.

where

$$
\begin{aligned}
& \mathrm{M}(\mathrm{q})=\left[\sum_{\mathrm{i}=1}^{5}\left(\mathrm{~J}_{\mathrm{Ti}}^{\mathrm{T}} \mathrm{m}_{\mathrm{i}} \mathrm{J}_{\mathrm{Ti}}+\mathrm{J}_{\mathrm{Ri}}^{\mathrm{T}} \Theta_{\mathrm{ci}} \mathrm{J}_{\mathrm{Ri}}\right)\right]_{5 \times 5} \\
& \mathrm{C}(\mathrm{q}, \dot{\mathrm{q}})=\left[\mathrm{c}_{1}, \mathrm{c}_{2}, . ., \mathrm{c}_{5}\right]^{\mathrm{T}}, \quad \mathrm{c}_{\mathrm{j}}=\sum_{\mathrm{k}, \mathrm{l}=1}^{5}(\mathrm{k}, 1 ; \mathrm{j}) \dot{\mathrm{q}}_{\mathrm{k}} \dot{\mathrm{q}}_{1}, \quad(\mathrm{k}, \mathrm{l} ; \mathrm{j})=\frac{1}{2}\left(\frac{\partial \mathrm{m}_{\mathrm{kj}}}{\partial \mathrm{q}_{1}}+\frac{\partial \mathrm{m}_{\mathrm{lj}}}{\partial \mathrm{q}_{\mathrm{k}}}-\frac{\partial \mathrm{m}_{\mathrm{kl}}}{\partial \mathrm{q}_{\mathrm{j}}}\right) \\
& \mathrm{G}(\mathrm{q})=\left[\mathrm{g}_{1}, \mathrm{~g}_{2}, \ldots, \mathrm{g}_{5}\right]^{\mathrm{T}}, \quad \mathrm{g}_{\mathrm{j}}=\frac{\partial \Pi}{\partial \mathrm{q}_{\mathrm{j}}}
\end{aligned}
$$

where $\mathrm{m}_{\mathrm{i}}, \mathrm{J}_{\mathrm{Ti}}, \mathrm{J}_{\mathrm{Ri}}$ are mass, translational Jacobian, and rotational Jacobian of link $\mathrm{i}$; $\theta_{\mathrm{ci}}$ is the inertia tensor of link $i$ with respect to the frame that expressed in link $i$ with origin at its center of mass; $\mathrm{I}=1, . ., 5 ; \Pi$ is the potential energy of the system; $\mathrm{q}, \dot{\mathrm{q}}, \ddot{\mathrm{q}}$ are vectors of the joint positions (7), velocities, accelerations, respectively; $(k, 1 ; j)$ is Christoffel notations; $m_{k l}(k, 1=1, . ., 5)$ are elements of the mass matrix $M(q)$.

$$
\mathrm{U}=\left[\mathrm{U}_{1}, \mathrm{U}_{2}, . ., \mathrm{U}_{5}\right]^{\mathrm{T}}
$$

According to $[12,13]$, the elements of vector $U$ are the expressions of the control forces/torques that match the programed motion of the robot.

$$
\mathrm{Q}=\left[\mathrm{Q}_{1}, \mathrm{Q}_{2}, . ., \mathrm{Q}_{5}\right]^{\mathrm{T}} .
$$

The elements of the vector $\mathrm{Q}$ are the expressions of the generalized forces of the friction, disturbance forces as well as other non-conservative forces applying on the robot. In general, it is hard to build up exactly robot's dynamic equations because of difficulty to determine these forces. It means why the classic control algorithm have disadvantages and difficulties. As mentioned above, this paper will discuss the use of the fuzzy method to control MRM robot to 
deal with the lack of adequation as well as inaccuracy of components in robot's dynamic equations. For the purpose of comparison of the control laws, the classic control and fuzzy the control, in this work we assume that the generalized forces are generated of the friction and disturbance and can be obtained as follows:

$$
\begin{gathered}
\mathrm{Q}_{\mathrm{fr}}=\mu\left[\dot{\mathrm{q}}_{1}, \ldots, \dot{\mathrm{q}}_{5}\right]^{\mathrm{T}} \\
\mathrm{Q}_{\text {dis }}=\delta\left[\sin \left(\mathrm{q}_{1}\right)+1, \cos \left(\mathrm{q}_{2}\right)+1, \sin \left(\mathrm{q}_{3}\right), \sin \left(\mathrm{q}_{4}\right) \cos \left(\mathrm{q}_{4}\right), \sin \left(2 \mathrm{q}_{5}\right)\right]^{\mathrm{T}}
\end{gathered}
$$

Then

$$
\mathrm{Q}=\mathrm{Q}_{\mathrm{fr}}+\mathrm{Q}_{\mathrm{dis}}
$$

(with $\mu=0.003$ and $\delta=0.5$ ).

It is important to note that the mentioned dynamical equations used to calculate control forces/moments of the robot based on the well-known computed torque control law. When applying fuzzy control, Q as unknown and dynamical equation is inadequate and inaccuracy.

\section{COMPUTED TORQUE CONTROL}

With MRM robot model as Figure 1, 3, the kinematic and dynamic problems are resolved to find out the links's motion trajectory and driving momen at the actuated joints with the purpose is the desired technical manipulation. Therefore, we need a control law to ensure welding gun following desired welding path in the Cartesian coordinate system of jig-robot's table, and comply the prescribed motion trajectory.

For the purpose of verifying, we first applying the classic control law, such as the computed torque control, to control MRM robot. We call the set $\mathrm{q}_{\mathrm{i}}(\mathrm{t})$ and $\dot{\mathrm{q}}_{\mathrm{i}}(\mathrm{t})$ are actuated joint's trajectory and velocity of MRM robot, $q_{i}^{d}(\mathrm{t}), \dot{q}_{i}^{d}(\mathrm{t}), \ddot{q}_{i}^{d}(\mathrm{t})$ are desired trajectory, velocity and accelerator. By virtue of dynamic equations (8) and $q_{i}^{d}(\mathrm{t}), \dot{q}_{i}^{d}(\mathrm{t}), \ddot{q}_{i}^{d}(\mathrm{t})$ which are obtain from inverse kinematics, computed torque control is designed with the purpose so that $\mathrm{q}_{\mathrm{i}}(\mathrm{t})$ and $\dot{q}_{i}(\mathrm{t})$ follow $q_{i}^{d}(\mathrm{t})$ and $\dot{q}_{i}^{d}(\mathrm{t})$, so welding gun follow desired welding path in the Cartesian coordinate system of jig-robot's table. The input of computed torque control are $\mathrm{q}_{\mathrm{i}}(\mathrm{t}), \dot{q}_{i}(\mathrm{t})$, $q_{i}^{d}(\mathrm{t}), \dot{q}_{i}^{d}(\mathrm{t}), \ddot{q}_{i}^{d}(\mathrm{t})$ and dynamical parameters in (8), output is driving momen set at actuated joints. We will use mediate variables $\mathrm{e}(\mathrm{t})$ and $\dot{e}(\mathrm{t})$ which are position error vector and velocity error of links. Now, control purpose will be controlling driving momen at initiative joints so that $\mathrm{e}(\mathrm{t})$ and $\dot{e}(\mathrm{t})$ are small as desire.

With position error and velocity error:

$$
\left\{\begin{array}{l}
\mathrm{e}_{\mathrm{i}}(\mathrm{t})=\mathrm{q}_{\mathrm{i}}(\mathrm{t})-\mathrm{q}_{\mathrm{i}}^{\mathrm{d}}(\mathrm{t}) \\
\dot{\mathrm{e}}_{\mathrm{i}}(\mathrm{t})=\dot{\mathrm{q}}_{\mathrm{i}}(\mathrm{t})-\dot{\mathrm{q}}_{\mathrm{i}}^{\mathrm{d}}(\mathrm{t})
\end{array}\right.
$$

With dynamical equations (8), we choose the control law as follows:

$$
\mathrm{u}=\mathrm{M}(\mathrm{q}) \mathrm{v}+\mathrm{C}(\mathrm{q}, \dot{\mathrm{q}})+\mathrm{G}(\mathrm{q})+\mathrm{Q}
$$

where

$$
v=\ddot{q}^{d}-K_{P} e-K_{D} \dot{e}
$$

The matrices $K_{D}, K_{P}$ are positive diagonal. 


$$
\mathrm{K}_{\mathrm{p}}=\operatorname{diag}\left\{\mathrm{k}_{\mathrm{p} 1}, \mathrm{k}_{\mathrm{p} 2}, . ., \mathrm{k}_{\mathrm{pn}}\right\} ; \mathrm{K}_{\mathrm{D}}=\operatorname{diag}\left\{\mathrm{k}_{\mathrm{D} 1}, \mathrm{k}_{\mathrm{D} 2}, . ., \mathrm{k}_{\mathrm{Dn}}\right\} ; \mathrm{k}_{\mathrm{pi}}>0 ; \mathrm{k}_{\mathrm{Di}}>0
$$

Applying computed torque control into MRM robot

We choose $\mathrm{K}_{\mathrm{D}}$ and $\mathrm{K}_{\mathrm{P}}$ for computed torque control module, as follows:

$$
\begin{gathered}
\mathrm{K}_{\mathrm{D}}=\operatorname{diag}\{451,450,431,465,435\} \\
\mathrm{K}_{\mathrm{P}}=\operatorname{diag}\{45,46,42,43,40\}
\end{gathered}
$$

The Position.mat, Velocity.mat, Accelerator.mat are files of position, velocity and acceleration which are obtained from kinematic analysis, using From File to insert them into Simulink as input data, those data are transformed into ComputerTorqueControl (block contain computed torque control) to calculate driving momen at actuated joints. After that, obtained momen will be transformed to Robot (MRM robot model) to calculate and find outreal position and velocity of links. Position and velocity are also responded to control module to compare with the desired position and velocity.

SIMULINK MODEL: Figure 4 shows the system of computed torque control.

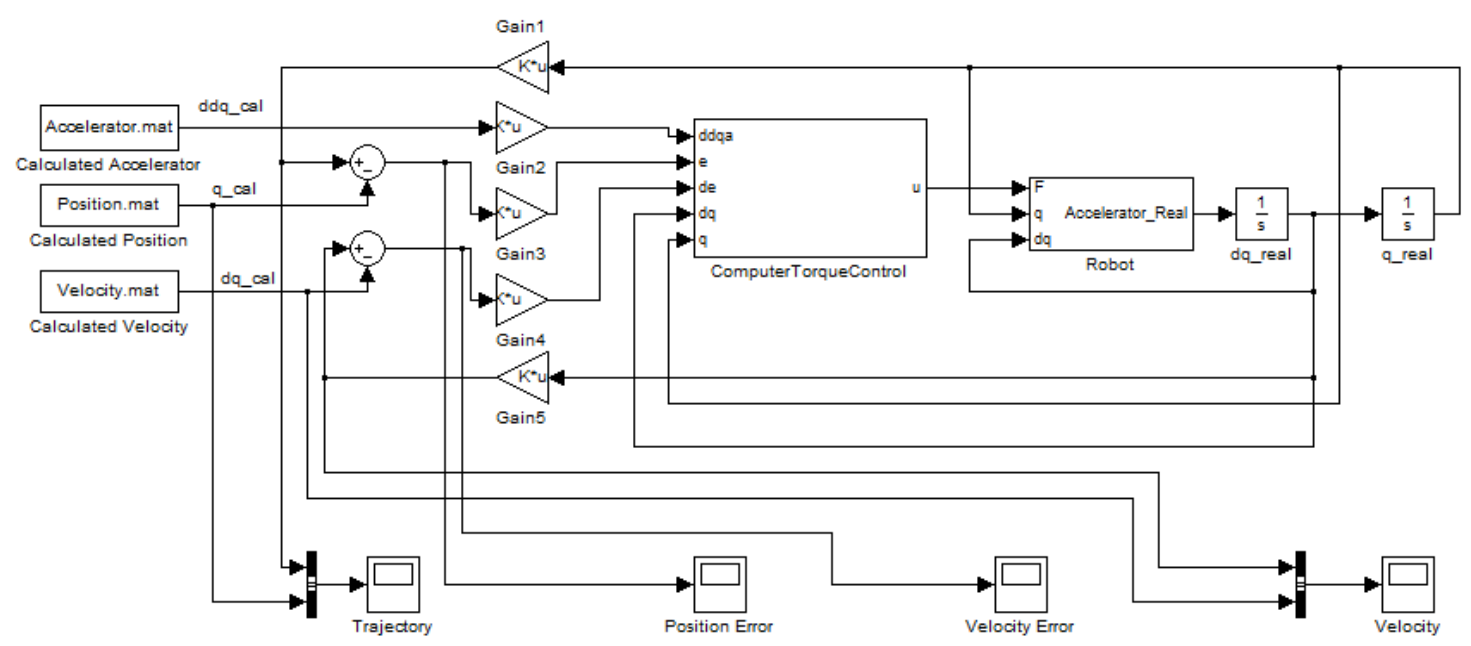

Figure 4. Simulink model of computed torque control.

The results are shown in figures from 7 to 10 in the next content with the aim is that comparing them with fuzzy control's results.

\section{FUZZY CONTROL}

In above section, computed torque control module is designed thanks to dynamical equations (8) to control MRM robot. However, determining dynamical parameters and building up dynamical equations are complicated. Moreover, dynamical parameters are difficult to determine exactly and many other intereferences impact on MRM robot which are difficult or cannot determine. In this part, fuzzy logic will be used to designed control module with purpose that declines the complexity and difficulty when contruct control module for MRM robot. We will use fuzzy control to find out desired control signals for MRM robot. Input parameters will be used as above.

- Summary fuzzy logic 
A Fuzzy Set $\mathrm{F}$ is determined in classical set $\mathrm{X}$ which its each element is a couple of value $(\mathrm{x}, \mu \mathrm{F}(\mathrm{x}))$, where: $\mu_{F}: X \rightarrow[0,1]$. [14]. Logical mapping $\mu_{F}$ is considered as membership function of fuzzy set $F$. Classic set $X$ is considered as base set of fuzzy set $F$.

Characteristic parameters of fuzzy set:

- The height (h) of fuzzy set $\mathrm{F}$ (define on base set $\mathrm{X}$ ) is value:

$$
h=\sup _{x \in X} \mu_{F}(x)
$$

- Determining domain (S) of fuzzy set F (define on base set $X$ ) is subset of $X$, satisfy:

$$
S=\sup p \mu_{F}(\mathrm{x})=\left\{\mathrm{x} \in \mathrm{X} \mid \mu_{F}(\mathrm{x})>0\right\}
$$

- $\quad$ Trusted domain (T) of fuzzy set $F$ (define on base set $\mathrm{X}$ ) is subset of $\mathrm{X}$, satisfy:

$$
T=\left\{\mathrm{x} \in \mathrm{R} \mid \mu_{F}(\mathrm{x})=1\right\}
$$

The common forms of membership function: Triangle membership function, trapezium form, Gauss form, Sign form, Sigmoidial form, Campanulate form.

Operations on fuzzy set: Unions of two fuzzy sets, intersection of two fuzzy sets, complement of two fuzzy sets.

Linguistic variable: Apart from describing variable by physical values (apparent values), they also can be demonstrated by linguistic values (fuzzy values). Each linguistic value is demonstrated by fuzzy set, has base set which is physical domains.

Composite lawsystem: A composite law system is described by n clause: [14]

$\mathrm{R}_{\mathrm{i}}$ : If ... then ... or

$\mathrm{R}_{\mathrm{n}}$ : If ... then ... (where $\left.\mathrm{I}=1 \ldots \mathrm{n}-1\right)$

Setting $B_{i}$ and $\mu_{i}$ as Fuzzy Set and membership function of composite law $R_{i}$. Meanwhile Fuzzy Set R' of composite law system[14]:

$$
\mathrm{R}^{\prime}=\mathrm{B}_{1}^{\prime} \cup \mathrm{B}_{2}^{\prime} \cup \ldots \cup \mathrm{B}_{\mathrm{n}}^{\prime}
$$

The common composite law systems: MAX-MIN, MAX-PROD, SUM-MIN, SUM-PROD.

To calculate membership function $\mu_{R^{\prime}}(\mathrm{y})$ of output value R' of a composite law system which has $\mathrm{n}$ composite laws $\mathrm{R}_{1}, \ldots, \mathrm{R}_{\mathrm{n}}$, the first we compute $\mu_{\mathrm{B}^{\prime}}(\mathrm{y})$, then calculate $\mu_{R^{\prime}}(\mathrm{y})$ follow choosen composite law, base on membership function's calculated formulas of two fuzzy sets.

Common calculated formulas $\mu_{\mathrm{B}^{\prime}}(\mathrm{y})$ in enginerring for a composite clause $B^{\prime}=A \Rightarrow B$ :

$$
\begin{aligned}
& \mu\left(\mu_{A}, \mu_{B}\right)=\min \left(\mu_{A}, \mu_{B}\right) \\
& \mu\left(\mu_{A}, \mu_{B}\right)=\mu_{A} \mu_{B}
\end{aligned}
$$
method.

Defuzzification: Common defuzzification methods are maxima method and barycentric

- Applying fuzzy logic for controlling MRM robot

Step 1: Determining input and output

The input of fuzzy control module include e $(\mathrm{t})$ and $\dot{e}(\mathrm{t})$, are position error and velocity error of links, are used as above. The output is adjusted momen at initiative joints so that e and $\dot{e}$ are small as desire. Supposing real momen need to set at initiative joints are $\tau_{i}$ to e and $\dot{e}$ come to 0 , 
theoretical driving momen set at initiative joints are $\tau_{i}^{d}$ to e and $\dot{e}$ come to 0 . So, adjusted momen at initiative joints is value which present for the diference of $\tau_{i}$ and $\tau_{i}^{d}$ :

$$
u_{i}=\tau_{i}-\tau_{i}^{d}
$$

Now, we can consider control module's input are e(t) and $\dot{e}(\mathrm{t})$, output is $\mathrm{u}(\mathrm{t})$. With each couple of values e(t) and $\dot{e}(\mathrm{t})$, control module will calculate adjusted momen at initiative joints and export a signal $\mathrm{u}(\mathrm{t})$ to adjust $\mathrm{e}(\mathrm{t})$ and $\dot{e}(\mathrm{t})$ come to asymptotic point with 0 :

$$
e=\left[e_{1}, \ldots, e_{5}\right]^{T}
$$

with: $\mathrm{e}_{1}, \mathrm{e}_{2}, \mathrm{e}_{3}$ are position error of tool-robot's links respectively.

$\mathrm{e}_{4}, \mathrm{e}_{5}$ are position error of jig-robot's links respectively.

$$
d e=\left[\dot{e}_{1}, \ldots, \dot{e}_{5}\right]^{T}
$$

with: $\dot{e}_{1}, \dot{e}_{2}, \dot{e}_{3}$ are velocity error of tool-robot's links respectively.

$\dot{e}_{4}, \dot{e}_{5}$ are velocity error of jig-robot's links respectively.

$$
u=\left[u_{1}, \ldots, \mathrm{u}_{5}\right]^{T}
$$

with: $\mathrm{u}_{1}, \ldots, \mathrm{u}_{5}$ are adjusted momen and force at MRM robot's joints respectively.

Base on the mass, desired trajectory and velocity of each link, we estimate physical domain of input and output variables as shown in Table 4.

Table 4. Physical domain of input and output variables.

\begin{tabular}{|c|c|c|c|}
\hline Link & $\mathrm{e}_{\mathrm{i}}$ & $\dot{e}_{\mathrm{i}}$ & $\mathrm{u}_{\mathrm{i}}$ \\
\hline 1 & {$[\min , \max ](\mathrm{deg})$} & {$[\min , \max ](\mathrm{deg} / \mathrm{s})$} & {$[\min , \max ](\mathrm{N} \cdot \mathrm{m})$} \\
\hline 2 & {$[\min , \max ](\mathrm{deg})$} & {$[\min , \max ](\mathrm{deg} / \mathrm{s})$} & {$[\min , \max ](\mathrm{N} \cdot \mathrm{m})$} \\
\hline 3 & {$[\min , \max ](\mathrm{mm})$} & {$[\min , \max ](\mathrm{mm} / \mathrm{s})$} & {$[\min , \max ](\mathrm{N})$} \\
\hline 4 & {$[\min , \max ](\mathrm{deg})$} & {$[\min , \max ](\mathrm{deg} / \mathrm{s})$} & {$[\min , \max ](\mathrm{N} \cdot \mathrm{m})$} \\
\hline 5 & {$[\min , \max ](\mathrm{deg})$} & {$[\min , \max ](\mathrm{deg} / \mathrm{s})$} & {$[\min , \max ](\mathrm{N} \cdot \mathrm{m})$} \\
\hline
\end{tabular}

Step 2: Fuzzificating input and output

Choosing the number of linguistic variables so that it is not too big and not so small, because if choosing the number of linguistic variables is too big then composite law system will be complicated and difficult to present law system, computed mass is big. If choosing the number of linguistic variables is so small then it cannot demonstrate all of features of system and adjustment will not smooth.

Fuzzificating $e(t)$ : physical domain of $\mathrm{e}_{\mathrm{i}}$ (with $\mathrm{i}=1 . .5$ ) is devided into 5 sub-domains. Each physical domain $X_{j}$ (sub-domain of physical domain of $e_{i}$ ) demonstates a fuzzy set $F_{j}$. Each fuzzy set $F_{j}$ describes a linguistic value. ( $j=1 . .5$ because we devide physical domain of $e_{i}$ into 5 sub-domains)

We will have 5 linguistic values which demonstrate for $\mathrm{e}_{\mathrm{i}}$, using symbols for 5 linguistic values:
AL: big negative
AN: small negative
Z: zero
DN: small positive
DL: big positive 
Therein: AL, AN, Z, DN, DL are linguistic values which are demonstrated by fuzzy sets $F_{1, \ldots}, F_{5}$ respectively. With $F_{1}, \ldots, F_{5}$ are fuzzy sets which determine on base sets $X_{1}, \ldots, X_{5}$ respectively. The value of physical domain increases gradually fom $\mathrm{X}_{1}$ to $\mathrm{X}_{5}$. Choosing triangle membership function, we perform as shown on Figure 5:

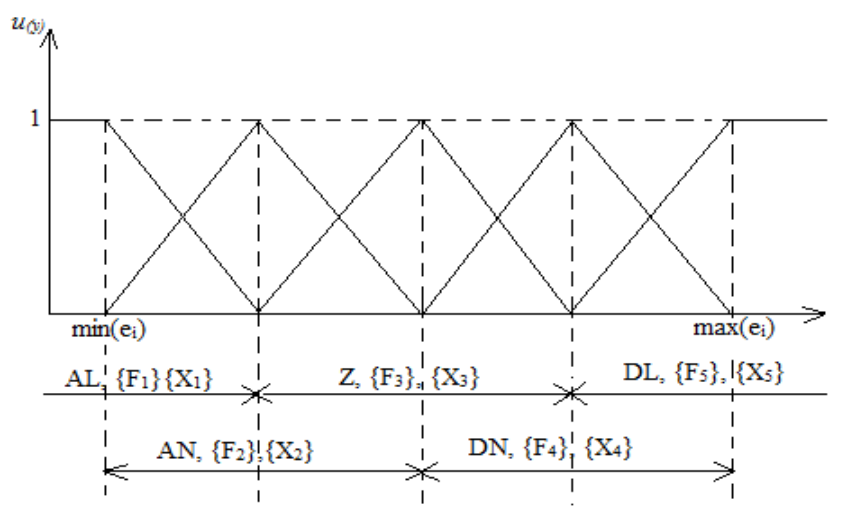

Figure 5. The membership function.

So, position error vector e(t) of MRM robot's 5 links are fuzzificated by 5 linguistic values as above. In spite of linguistic values' name are the same for $\mathrm{e}_{\mathrm{i}}$, but physical domains desmostrate them which are different.

With $\dot{e}(\mathrm{t})$ and $\mathrm{u}(\mathrm{t})$, we also do the same, and hence, with each $\mathrm{e}_{\mathrm{i}}, \dot{e}_{\mathrm{i}}, \mathrm{u}_{\mathrm{i}}$ we use 5 linguistic values to present. In the same way, in spite of linguistic values' name are similar for e(t), $\dot{e}(\mathrm{t})$, $\mathrm{u}(\mathrm{t})$, but physical domains desmostrate them which are different.

Step 3: Build up control law

We build up the composite law system for MRM robot. Variables $\mathrm{e}_{\mathrm{i}}, \dot{e}_{\mathrm{i}}$ and $\mathrm{u}_{\mathrm{i}}$ will be demonstrated by 5 linguistic values as above, its' composite law system is presented in FAM table. If the value of $\mathrm{e}_{\mathrm{i}}$ and $\dot{e}_{\mathrm{i}}$ belong to physical domain which demonstrates a linguistic value in $\{\mathrm{AL}, \mathrm{AN}, \mathrm{Z}, \mathrm{DN}, \mathrm{DL}\}$ of each variable then control module will also give control signal $\mathrm{u}_{\mathrm{i}}$, with its' value belong to physical domain which demonstrates a linguistic value in $\{\mathrm{AL}, \mathrm{AN}, \mathrm{Z}, \mathrm{DN}$, DL $\}$ of it to adjust the value of $e_{i}$ and $\dot{e}_{\mathrm{i}}$ so that they come gradually to physical domain which demonstrates linguistic value $\mathrm{Z}$. In other words, its' physical value come gradually to asymptotic domain of 0 . The composite law system of fuzzy control is described in Table 5.

Table 5. FAM table present the composite law system (GTNN: linguistic values).

\begin{tabular}{|c|c|c|c|c|c|}
\hline GTNN & AL & AN & Z & DN & DL \\
\hline AL & DL & DL & DL & DN & Z \\
\hline AN & DL & DN & DN & Z & AN \\
\hline Z & DL & DN & Z & AN & AL \\
\hline DN & DN & Z & AN & AN & AL \\
\hline DL & Z & AN & AL & AL & AL \\
\hline
\end{tabular}


If we just control one link, this is quite easy to draw the control law because adusted law of $\mathrm{u}_{\mathrm{i}}$ will be proportional to $\mathrm{e}_{\mathrm{i}}$ and $\dot{e}_{\mathrm{i}}$. However, paper's aim is that controlling 5DOF MRM robot, its' links have kinematic and dynamic relation together, so the changed rules of $u(t)$ may no longer proportional to $\mathrm{e}_{\mathrm{i}}(\mathrm{t})$ and $\dot{e}_{\mathrm{i}}(\mathrm{t})$. After some tests, a suitable control law for 5DOF MRM robot is chosen and presented as FAM Table 4:

Thanks to FAM table, we have a composite law system, including 25 composite clauses:

$R_{l}$ : If $e(t)$ is $A L$ and $\dot{e}(t)$ is $A L$ then $u(t)$ is $D L$ or

...

$R_{25}$ : If $e(t)$ is $D L$ and $\dot{e}(t)$ is $D L$ then $u(t)$ is $A L$.

Step 4: Determining composite device

Due to 5 linguistic values $\{\mathrm{AL}, \mathrm{AN}, \mathrm{Z}, \mathrm{DN}, \mathrm{DL}\}$ are demonstrated by physical domains $\left\{\mathrm{X}_{1}, \ldots, \mathrm{X}_{5}\right\}$, but physical domains $\mathrm{X}_{1}, \ldots, \mathrm{X}_{5}$ intersect as presented above. So, input values $\mathrm{e}_{\mathrm{i}}$ and $\dot{e}_{\mathrm{i}}$ are at one moment those always belong to two domains in $\left\{\mathrm{X}_{1}, \ldots, \mathrm{X}_{5}\right\}$. In other words, $\mathrm{e}_{\mathrm{i}}$ and $\dot{e}_{\mathrm{i}}$ are at one moment those always belong to two fuzzy sets which demonstrate any two linguistic values in 5 above linguistic values. Therefore, each composite law will have different dependence when $\mathrm{e}_{\mathrm{i}}$ and $\dot{e}_{\mathrm{i}}$ are putted on control module. We need determine dependence of each composite law and dependence of whole composite law system to find out output's dependence when putting input on control module. Composite device will be used to do this. This paper choose composite law MAX-MIN. Calculating each composite law's dependence by formula (25) and computing whole above composite law system's dependence by MAX rule as under:

$$
\mu_{A \cup B}(\mathrm{x})=\max \left\{\mu_{A}(\mathrm{x}), \mu_{B}(\mathrm{x})\right\}
$$

\section{Step 5: Defuzzification}

The output of composite law block is the dependence. We need defuzzificate to obtain output's physical value. This paper uses barrycentric defuzzification method and triangle membership function because they give believable results in the simple way. This method will give physical value $\mathrm{y}^{\prime}$, is barycentric point's abscissa of range which is created by $\mu_{\mathrm{B}}(\mathrm{y})$ horizontal axe. The formula to determine y':

$$
y^{\prime}=\frac{\int_{S} y \mu_{B^{\prime}}(\mathrm{y}) \mathrm{dy}}{\int_{S} \mu_{B^{\prime}}(\mathrm{y}) \mathrm{dy}}
$$

Applying: Position.mat and Velocity.mat are calculated trajectory, velocity which are obtained from Maple.Torque.mat, PhysicalDomains are set of momen's approximate values, block give approximately physical values of input and output respectively. Fuzzy_Control is the block which contains fuzzy control module, Robot is MRM robot model.

The results are shown from Figure 7 to 10 in the next content with the aim is that comparing them with computed torque control's results.

SIMULINK MODEL: Figure 6 shows the system offuzzy control applying to control MRM robot. 


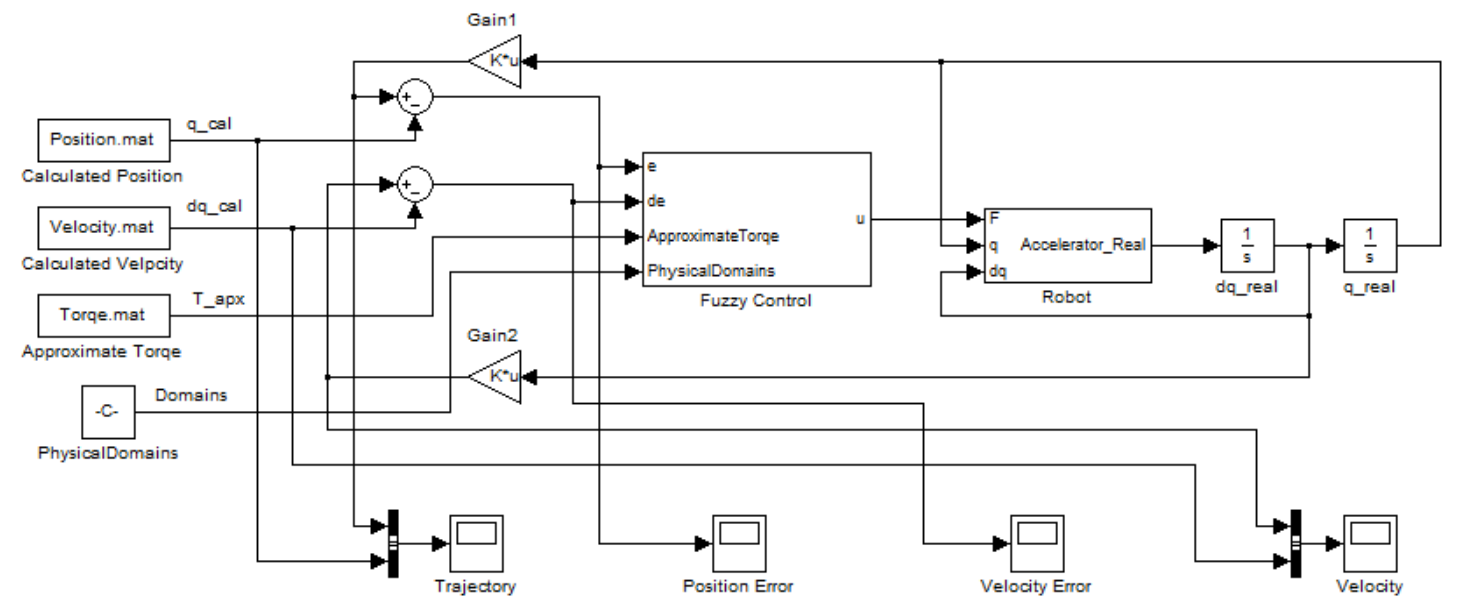

Figure 6. Simulink model of fuzzy control module.

\section{SIMULATION RESULTS}

For the case of MRM robot presented in Figure 1, 3, their geometrical and inertial parameters are designed as follows (links are homogeneous, sections are unchanged), Table 6, 7:

Table 6. Geometrical and inertial parameters of MRM robot.

\begin{tabular}{|c|c|c|c|c|c|c|c|c|}
\hline \multirow[t]{2}{*}{ Link } & \multirow[t]{2}{*}{ Shape } & \multicolumn{3}{|c|}{ Dimension of links } & \multirow[t]{2}{*}{$\begin{array}{c}\text { Weight } \\
(\mathrm{kg})\end{array}$} & \multicolumn{3}{|c|}{$\begin{array}{c}\text { Coordinates of links' } \\
\text { barycenter on local } \\
\text { Cartesian coordination } \\
\text { system }\end{array}$} \\
\hline & & \multicolumn{2}{|c|}{ Section (m) } & $\begin{array}{c}\text { Length/ } \\
\text { Thickness (m) }\end{array}$ & & $\mathrm{x}(\mathrm{m})$ & $y(m)$ & $\mathrm{z}(\mathrm{m})$ \\
\hline 11 & Rectangular girder & 0.03 & 0.02 & 0.33 & 8 & -0.165 & 0 & 0 \\
\hline 12 & Rectangular girder & 0.03 & 0.02 & 0.33 & 8 & -0.165 & 0 & 0 \\
\hline 13 & Rectangular girder & 0.02 & 0.01 & 0.4 & 3.5 & 0 & 0 & 0.2 \\
\hline 21 & Half of Cylinder & \multicolumn{2}{|c|}{0.08} & 0.3 & 50 & 0 & 0 & -0.15 \\
\hline 22 & Dick & \multicolumn{2}{|c|}{0.06} & 0.05 & 20 & 0 & 0 & -0.05 \\
\hline
\end{tabular}

Table 7. Physical domain of input and output variables.

\begin{tabular}{|c|c|c|c|}
\hline Link & $\mathrm{e}_{\mathrm{i}}$ & $\dot{e}_{\mathrm{i}}$ & $\mathrm{u}_{\mathrm{i}}$ \\
\hline 1 & {$[-2,2](\mathrm{deg})$} & {$[-2,2](\mathrm{deg} / \mathrm{s})$} & {$[-25,25](\mathrm{N} \cdot \mathrm{m})$} \\
\hline 2 & {$[-2,2](\mathrm{deg})$} & {$[-2,2](\mathrm{deg} / \mathrm{s})$} & {$[-25,25](\mathrm{N} \cdot \mathrm{m})$} \\
\hline 3 & {$[-2,2](\mathrm{mm})$} & {$[-2,2](\mathrm{mm} / \mathrm{s})$} & {$[-25,25](\mathrm{N})$} \\
\hline 4 & {$[-2,2](\mathrm{deg})$} & {$[-2,2](\mathrm{deg} / \mathrm{s})$} & {$[-25,25](\mathrm{N} \cdot \mathrm{m})$} \\
\hline 5 & {$[-2,2](\mathrm{deg})$} & {$[-2,2](\mathrm{deg} / \mathrm{s})$} & {$[-30,30](\mathrm{N} \cdot \mathrm{m})$} \\
\hline
\end{tabular}


The results are shown from the Figure 7 to the Figure 10.

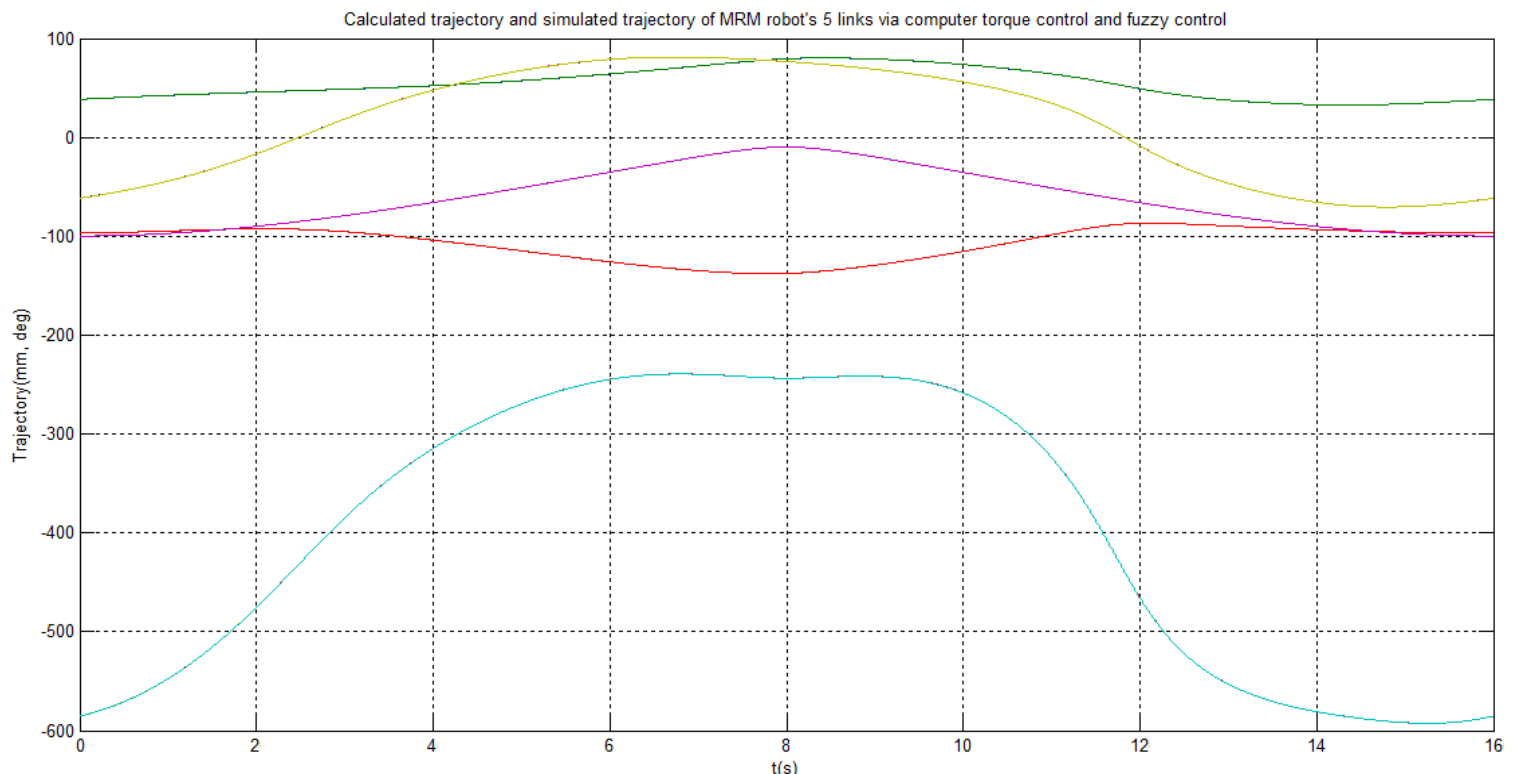

Figure 7. Graph of calculated and simulated trajectory of MRM robot's 5 links.

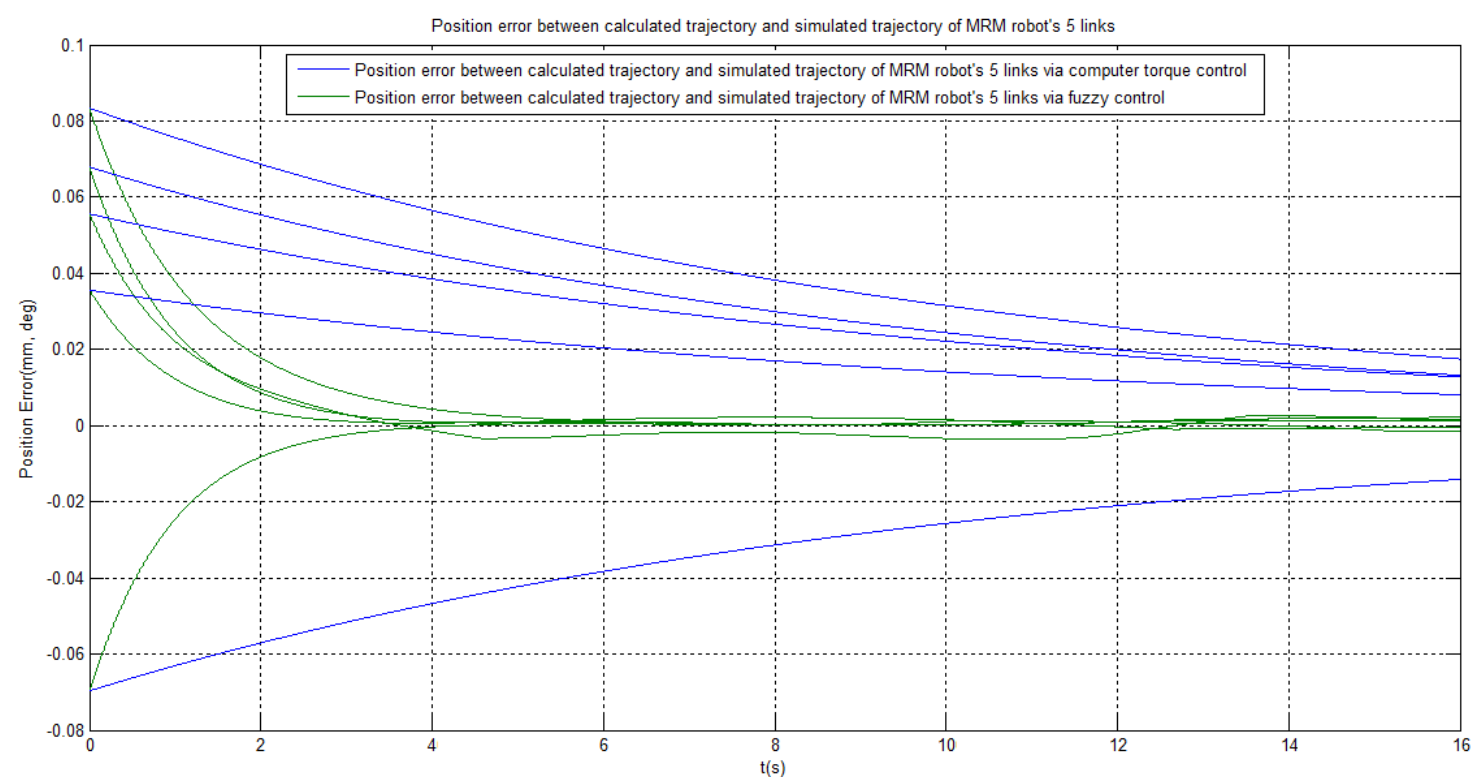

Figure 8. Graph of position error of MRM robot's 5 links. 


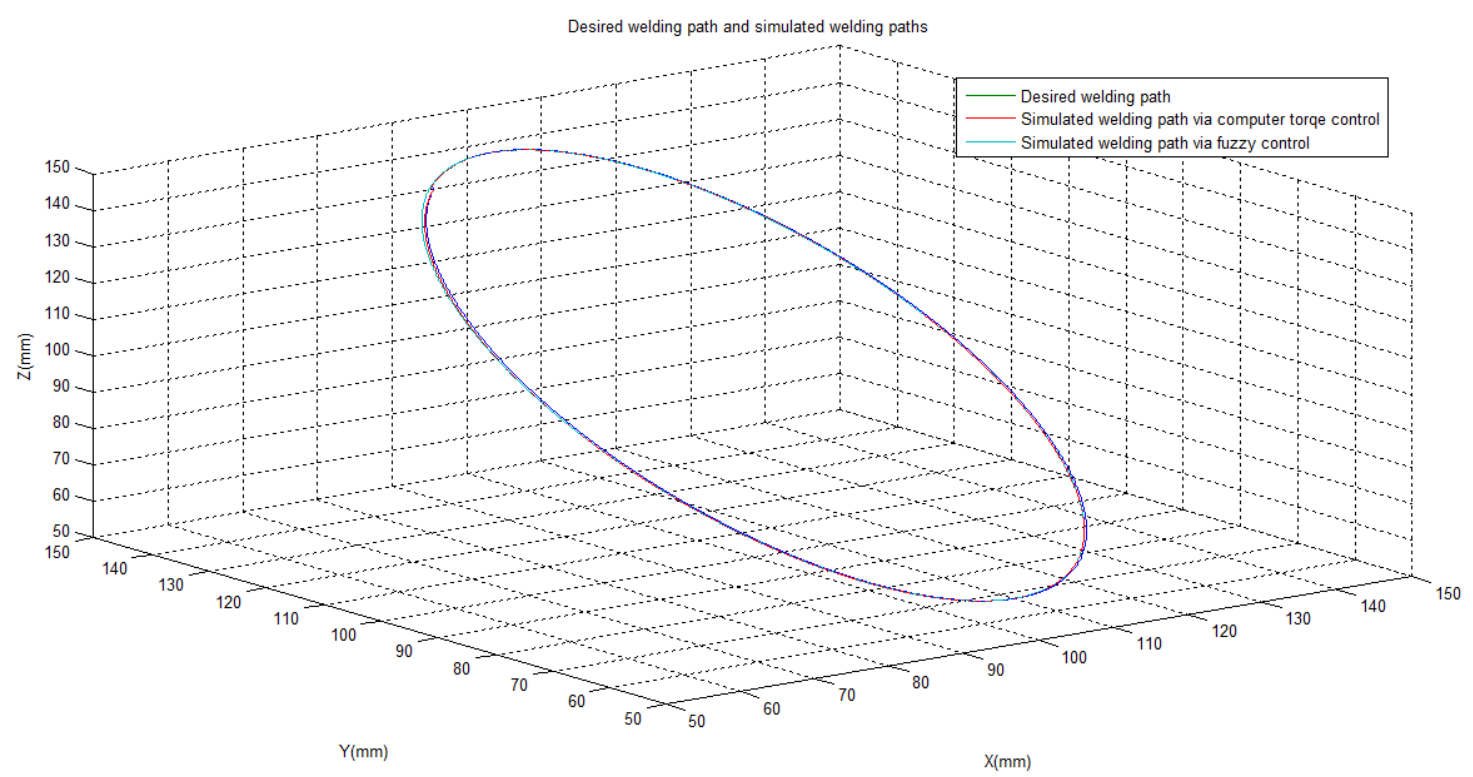

Figure 9. Calculated and simulated welding path in Cartesian coordinate system of jig-robot's table.

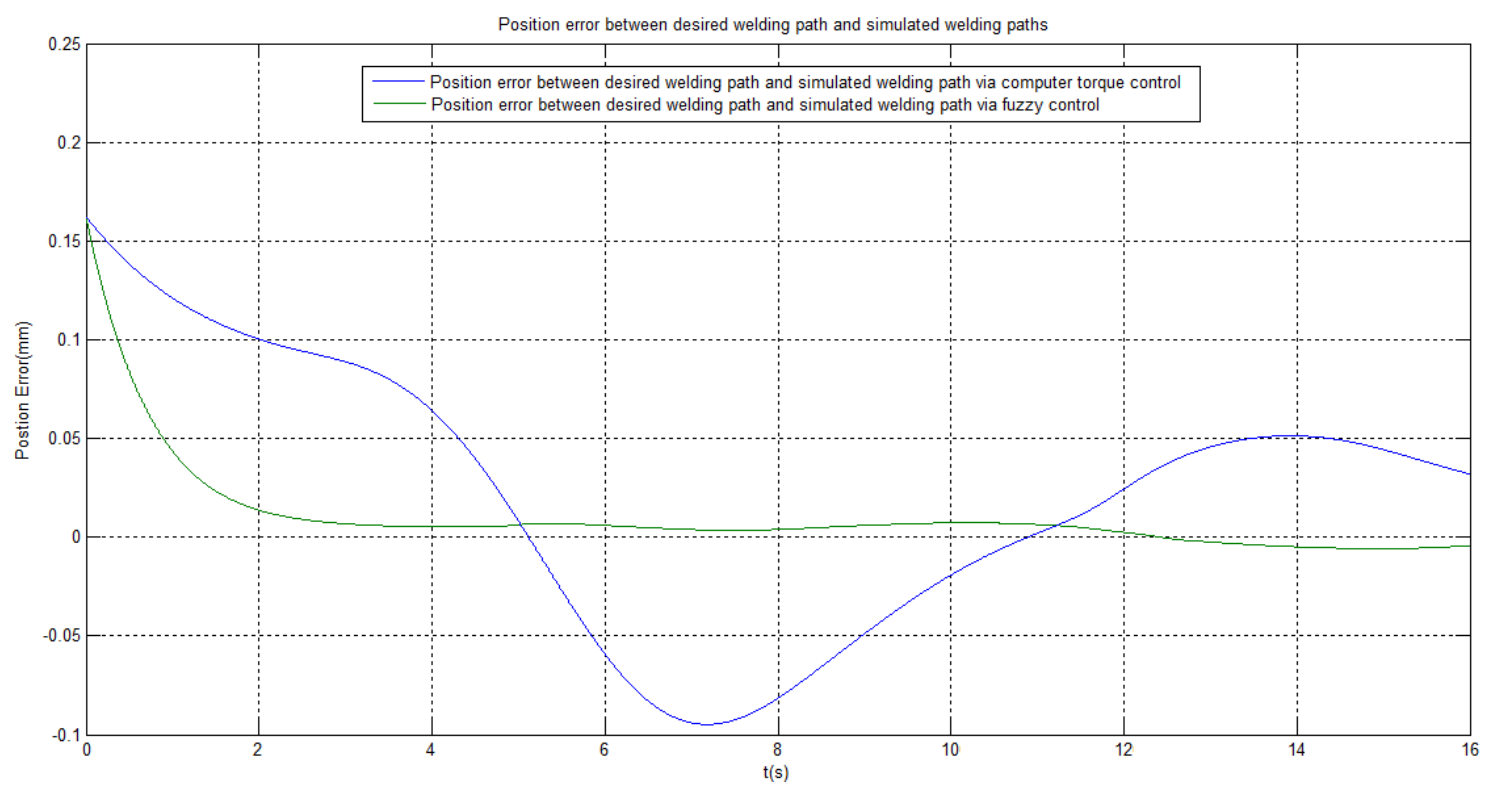

Figure 10. Position error between calculated welding path and real welding path.

\section{CONCLUSION}

The received results show that fuzzy control gives the relatively positive results in comparison with computed torque control about the accuracy. Moreover, undeniable benefit's fuzzy control is that we do not use dynamic equations when buiding up control module and we do not need to use accuracy and adequate dynamic equations in control process. This is particularly meaning when applying to control engineering systems that we cannot determine 
exact mathematical euquations of control object. In this paper, fuzzy control's input and output are fuzzificated by 5 linguistic values. If we use more linguistic values then the accuracy and the smooth of signal are higher. The paper's analysis and result contribute a meaning part in the expansion of research and application of modern theories in controlling complex robots such as MRM robot. This is base for the next studies, authors will research the combination of fuzzy logic and some other theories such as Hedge Algebras, Neural Network, Genetic Algorithm to optimize control method. The results of these researching will be presented in next papers.

\section{REFERENCES}

1. Phan Bui Khoi - Calculation and simulation the program motion of mechanisms of relative manipulation (MRM), Journal of Science and Technology 47 (3) (2009) 19-28.

2. Phan Bui Khoi - Kinematic problems of programming control of mechanism of relative meanipulation, Proceedings of National Conference on Mechanics, Proceedings of National Conference on Mechanics 2 (2009) 317-323.

3. Afonin V. L., Phan Bui Khoi - Method for calculating action and constrained reactions forces in mechanisms of relative manipulation while executing programming motion, IMASH. RAS, Moscow, 1997.

4. Phan Bui Khoi-- Applying Principle of Compatibility for analyzing forces of Mechanism of Relative Manipulation Robot. Thesis of PhD. IMASH. RAS, Moscow, 1997.

5. Phan Bui Khoi - Dynamical investigation of relation manipulation mechanisms in mechanical processing. Proceedings of National Conference on Mechanics 1 (2004) 181-190.

6. Mamdani E. H. - Twenty Years of Fuzzy Control: Experiences Gained and Lessons Learnt, IEEE Intl. Conf. on Fuzzy Systems, 1993, pp. 339-344.

7. Wang L. X. - Stable adaptive fuzzy control of nonlinear systems, IEEE Transactions on Fuzzy Systems- 1 (1993) 146-155.

8. Su C. Y. and Stepanenko Y. - Adaptive control of a class of nonlinearsystems with fuzzy logic, IEEE Transactions- on Fuzzy Systems- 2 (1994) 285-294.

9. Yang Y. S., Jia X. L., and Zhou C. J. - Robust adaptive fuzzy control for a class of uncertain nonlinear systems, Proceedings of the 4th Int. Conf. Intelligent Techniques Soft Computing Nuclear Science Engineering, Bruges, Belgium, 2000, pp. 303-311.

10. Takagi T. and Sugeno M. - Fuzzy identification of systems and its applicationsto modeling and control, IEEE Trans. Syst., Man., Cybern.-15 (1985)-116-132.

11. Wang L. X. - A Course in Fuzzy Systems and Control, Upper SaddleRiver, NJ: PrenticeHall, 1997.

12. Do Sanh - On the principle of compatibility and the equation of a constrained mechanical system, ZAMM (1980) 210-212.

13. Do Sanh - On the motion of controlled mechanical system. Advances in Mechanics. Warsaw 7 (2) (1984) 3-24.

14. Keung-Chi Ng, Bruce Abramson - Uncertainty Management in Expert Systems, IEEE Expert 5 (2) (1990) 29-48. 


\title{
TÓM TẮT
}

\section{ÚNG DỤNG LOGIC MỜ TRONG ĐIÊU KHIỂN ROBOT TÁC HỢP (MRM ROBOT)}

\author{
Phan Bùi Khôi ${ }^{1}$, Nguyễn Văn Toản ${ }^{2}$ \\ ${ }^{1}$ Đại học Bách khoa Hà Nội (HUST), Số 1 Đại Cồ Việt, Hai Bà Trung, Hà Nội \\ ${ }^{2}$ Korea Institute of Science and Technology, 5 Hwarang-ro 14-gil, Seongbuk-gu, Seoul, \\ Republic of Korea
}

Email: khoi.phanbui@hust.edu.vn ${ }^{1}$,toan70411hd91@gmail.com ${ }^{2}$

Trong điều khiển robot, các mô hình toán học biểu diễn trạng thái động lực của robot thường phức tạp. Các các đại lượng trong các phương trình động lực học của robot như các ma trận quán tính, lực ma sát,... khó có thể xác định chính xác. Với các robot có cấu trúc phức tạp như robot song song, robot tác hợp,... thì việc thiết lập phương trình động lực của robot càng khó khăn và nhiều khi không nhận được một cách đầy đủ. Trong trường hợp đó, điều khiển robot là khá khó khăn. Ứng dụng logic mờ vào việc điều khiển robot có thể khắc phục được khó khăn đó. Thuật toán điều khiển mờ cho khả năng xử lí sự thiếu đầy đủ và thiếu chính xác của các yếu tố ảnh hưởng trong phương trình động lực học của robot. Hơn thế nữa, các luật mờ được sinh ra bởi các mệnh đề dựa trên logic của con người nên nó khá dễ hiểu và dễ thực hiện. Bài báo này trình bày việc áp dụng logic mờ vào điều khiển robot tác hợp. Để kiểm tra độ tin cậy của những kết quả thu được từ bộ điều khiển mờ, bài báo trình bày việc áp dụng điều khiển kinh điển (điều khiển lực) vào điều khiển robot tác hợp để so sánh.

Tù khóa: robot tác hợp (MRM), logic mờ, điều khiển mờ. 